\title{
AVALIAÇÃO CLINICA DO DICLORIDRATO DE FLUFENAZINA
}

\author{
Waldir de Sousa E Almeida *
}

As observações aqui relatadas foram feitas em psicóticos crônicos já submetidos, em outras oportunidades, a variados tratamentos psiquiátricos; alguns já submetidos à leucotomia por via transorbitária e, um dêles, à impregnação por derivados fenotiazínicos e pelo Serpasol. Alguns contavam com várias evasões.

\author{
MATERIAL E MÉTODO
}

Empregamos o dicloridrato de flufenazina ** em 12 doentes, 8 da raça branca, 4 da raça negra ( 2 prêtos e 2 pardos). As idades variaram de um minimo de 27 a um máximo de 63 anos. Quatro pacientes tinham entre 32 e 39, cinco entre 41 e 50 e um tinha 62 anos.

O tempo da doença oscilou entre 8 e 26 anos, sendo a maioria com 10 a 17 anos ( 8 casos). Os diagnósticos situaram-se, na sua quase totalidade, no grupo das esquizofrenias: esquizofrenia hebefrênica (1); esquizofrenia catatônica (5); esquizofrenia hebefreno-catatônica (1); esquizofrenia paranóide (3); esquizofrenia hebefreno-paranóide (1); oligofrenia-mania (1).

Após exame clínico e exames hematológicos e de urina, encetávamos o tratamento com a finalidade de obter a sindrome de impregnação. A dose inicial foi de $5 \mathrm{mg}$, seguida, nos dias subseqüentes, de doses adicionais de $5 \mathrm{mg}$ por vez, até o aparecimento de sintomas extrapiramidais. Apenas um caso, o nosso primeiro paciente iniciou com $2,5 \mathrm{mg}$ e, durante 3 dias, recebeu aumentos subseqüentes 2,5 mg; contudo, ao atingir $10 \mathrm{mg}$, passamos a aumentos diários de $5 \mathrm{mg}$. Em três outros casos começamos com $10 \mathrm{mg}$ e mantivemos esta dose no segundo dia, passando, a seguir, para aumentos de $5 \mathrm{mg}$ diários.

As indicações para o tratamento não obedeceram a um critério seletivo rigoroso; contudo buscou-se dar certa ênfase aos casos de comportamento noturno inquieto, com deambulação, solilóquios, atitude autoritária, desconfiada, hostil, irascível e surtos de agravamento psicótico. Esses pacientes, em geral, lograram melhor benefício em comparação com aquêles de conduta passiva, cuja enfermidade apresentava evoluções insidiosas, sem episódios de maior exteriorização.

\section{TOLERÂNCIA}

Os hemogramas repetidos regularmente evidenciaram, de modo geral, um aumento dos eosinófilos e dos neutrófilos segmentados e diminuição, por vêzes acentuada, dos neutrófilos em bastonete, dos linfócitos e monócitos. Tal fato não trouxe,

Trabalho realizado na Colônia Juliano Moreira, do Serviço Nacional de Doenças Mentais: * Psiquiatra do S.N.D.M.

** O produto (Anatensol) foi gentilmente cedido por E. R. Squibb \& Sons. 
porém, quaisquer conseqüências clínicas assinaláveis. Os exames de urina, de regra, acusaram traços de urobilina e de pigmentos biliares. Em um caso apareceram traços de glicose na urina; contudo êste achado não foi mais comprovado em exames ulteriores.

Um dos pacientes apresentou, em duas ocasiões, diarréia: a primeira, com a dose de $45 \mathrm{mg}$, não foi acompanhada de outros sintomas e cedeu sem necessidade de interromper a impregnação; a segunda, com a dose de $115 \mathrm{mg}$, foi acompanhada de hipertermia $\left(40^{\circ} \mathrm{C}\right)$ e resistente à medicação; suspenso o tratamento, foi o paciente removido para a enfermaria clínica, a fim de ser medicado conforme o caso exigia.

Em três pacientes a temperatura manteve-se subnormal $\left(36^{\circ} \mathrm{C}\right)$ por alguns dias; um dêles manteve essa temperatura por mais dois dias após a suspensão do medicamento e, no terceiro dia, apresentou queda para $35,4^{\circ} \mathrm{C}$, logo normalizada. $\mathrm{Em}$ um paciente, a temperatura que, durante tôda impregnação fôra normal, ao ser retirada a medicação, baixou para $35,8{ }^{\circ} \mathrm{C}$, havendo também incontinência urinária que cedeu sem maiores conseqüências; sua dose de impregnação fôra inicialmente $10 \mathrm{mg}$; mantida a dose, cedeu espontâneamente o extrapiramidalismo; voltamos, então, a aumentar até atingir $50 \mathrm{mg}$, dose que foi mantida por 6 dias consecutivos.

No que diz respeito às variações da pressão arterial e pulso, não há informacões de monta a registrar; os valôres tensionais mantiveram-se dentro dos limites da normalidade, sendo assinaladas pequenas oscilaçóes de $2 \mathrm{~mm}$ além do valor inicial.

\section{RESULTADOS}

Dentro das sindromes clínicas estudadas, apresentaram melhor reação ao tratamento os casos de esquizofrenia paranólde. Os que não reagiram satisfatoriamente situaram-se no grupo dos catatônicos no qual somente um caso apresentou meIhora apreciável, tanto mais surpreendente pelas caracteristicas de que se revestiu. Vale assinalar que este paciente, ao iniciar seus primeiros contatos com o mundo exterior, foi para fazer queixas de que "um aparelho no corpo fazia transmissōes noturnas", prejudicando-lhe o sono.

Outro ponto a salientar diz respeito ao fato de que a melhoria apresentada pelos pacientes não guardou qualquer relação com a idade dos mesmos e o tempo calculado de doença.

\section{COMENTARIOS}

Empregamos em 12 casos de psicóticos crônicos o dicloridrato de flufenazina, um nôvo psicoplégico, com a finalidade de obter a síndrome de impregnação. As doses suscetíveis de provocar sintomas extrapiramidais situaram-se, predominantemente, dentro dos limites de 35 e $90 \mathrm{mg}$. A dose variou bastante e registramos impregnações com $10 \mathrm{mg}$ (1), $35 \mathrm{mg}$ (2), $40 \mathrm{mg}$ (1), $45 \mathrm{mg}$ (1), $50 \mathrm{mg}$ (3), $55 \mathrm{mg} \mathrm{(1),} 70 \mathrm{mg} \mathrm{(2),} 90 \mathrm{mg}$ (1). Ressaltamos a ocorrência do parkinsonismo com dose de $10 \mathrm{mg}$ em um paciente e o silêncio assintomático com dose de $240 \mathrm{mg}$ em paciente de raça negra.

Uma vez obtido o parkinsonismo, procurávamos manter a dose ótima por alguns dias (uma semana em média) e depois, passávamos à redução (de $10 \mathrm{em} 10 \mathrm{mg}$ ); quando a dose útil fôsse muito elevada, era reduzida à metade e depois de $10 \mathrm{em} 10 \mathrm{mg}$. As variações de temperatura, pressão 
arterial, bem como as alterações hematolögicas, não constituiram motivo de contra-indicação. Em geral, os sintomas extrapiramidais persistiam com a diminuição da dose; cascs houve em que, com $5 \mathrm{mg}$, as características sintomáticas continuaram presentes por vários dias. O periodo máximo de uso do medicamento foi de 86 dias e a duração da fase de maior intensidade dos sintomas parkinsonianos foi de 25 dias, em média. À exceção da diarréia ocorrida em um paciente motivando a suspensão do tratamento, a droga mostrou-se clìnicamente inócua, no sentido de não ter originado qualquer sindrome irreversivel.

Acreditamos, assim, seja o dicloridrato de flufenazina, elemento útil na terapêutica psiquiátrica, podendo ser empregado a longo prazo; encontrada a dose ótima para cada caso, a medicação deve ser mantida por longo periodo.

Verificamos que, em alguns pacientes, a suspensão da dose mínima útil, isto é, aquela situada abaixo da dose causadora de sintomas extrapiramidais, determinava o reaparecimento dos sintomas que tinham motivado a instituição do tratamento. Restabelecida a terapêutica desapareciam os sintomas. Alguns pacientes, sem qualquer dose de manutenção, conseguiram manter-se satisfatòriamente até a data em que registramos estas observações (outubro de 1961).

\section{RESUMO}

O autor apresenta dados preliminares de sua experiência com nôvo psicoplégico (dicloridrato de flufenazina), empregado em 11 esquizofrênicos e em um caso de oligofrenia. Os casos que melhor responderam ao tratamento foram os de esquizofrenia paranóide, não havendo relação entre dose empregada e a melhora clínica. As doses úteis, obtidas mediante aumento progressivo a partir de $5 \mathrm{mg}$ até o aparecimento de sintomas extrapiramidais, situaram-se entre 35 e $90 \mathrm{mg}$. Em um paciente da raça negra não foi possivel a impregnação, mesmo com dose de $240 \mathrm{mg}$ diários. O autor acredita ser o cloridrato de flufenazina elemento útil na terapêtica psiquiátrica, devendo ser empregado a longo prazo.

\section{SUMMARY}

\section{Clinical evaluation of fluphenazine dihydrochloride in management of psychotics.}

Preliminary data on the treatment with fluphenazine dihydrochloride are commented. The drug was given to 11 schizophrenic and one oligophrenic patients. The best results were obtained in paranoid schizophrenic cases. There was not correspondence between dosis and clinical improvement. The dosis used were increased progressively until extrapyramidal 
symptoms appeared. The initial dosis was $5 \mathrm{mg}$ and that one responsible for extrapyramidal symptoms varied between 35 and $90 \mathrm{mg}$. The author points out a case, of a negro patient, in which was not possible to get extrapyramidal symptoms, even with the daily dose of $240 \mathrm{mg}$. The author believes that fluphenazine dihydrochloride is a very useful drug in psychiatric patients and may be used in long term therapy.

Colônia Juliano Moreira - Jacarepaguá, Rio de Janeiro - Estado da Guanabara, Brasil. 